University of Wollongong

Research Online

Faculty of Engineering and Information

Faculty of Engineering and Information

Sciences - Papers: Part A

Sciences

$1-1-2014$

Suboptimal MPPT control for power management in PV-diesel remote area power supply systems

Yingjie Tan

University of Wollongong, yt816@uowmail.edu.au

Lasantha G. Meegahapola

University of Wollongong, lasantha.meegahapola@rmit.edu.au

Kashem M. Muttaqi

University of Wollongong, kashem@uow.edu.au

Follow this and additional works at: https://ro.uow.edu.au/eispapers

Part of the Engineering Commons, and the Science and Technology Studies Commons

Research Online is the open access institutional repository for the University of Wollongong. For further information contact the UOW Library: research-pubs@uow.edu.au 


\title{
Suboptimal MPPT control for power management in PV-diesel remote area power supply systems
}

\author{
Abstract \\ Maximum power point tracking (MPPT) is commonly being used in solar-photovoltaic (PV) power \\ generation systems to maximise solar energy extraction. In this paper it is proposed to operate the solar- \\ PV system at the suboptimal MPPT to manage power balance in a remote area power supply (RAPS) \\ system. This is performed based on three different operating modes: 1) Frequency control mode; 2) \\ Active power control mode; 3) MPPT control mode. The operating modes are decided based on the load \\ level and the operating mode of the diesel generator (i.e. synchronous condenser mode or generator \\ mode). This power management strategy balances the generation and load demand that requires \\ transition between the three operating modes without using the dummy load. The proposed strategy is \\ capable of extending the diesel generator life time and improves the operating efficiency of the diesel \\ generator. Simulation studies are carried out to validate the effectiveness of the suboptimal MPPT control \\ strategy in a PV-Diesel RAPS system, and have shown that the proposed strategy can seamlessly \\ maintain power balance in the RAPS system while maintaining the voltage and frequency within \\ stipulated limits. Substantial cost savings can also be achieved in long run due to the life time extension \\ and efficiency improvement of the diesel generator.
}

\section{Keywords}

mppt, systems, control, power, management, pv, diesel, suboptimal, remote, area, supply

\author{
Disciplines \\ Engineering | Science and Technology Studies
}

\section{Publication Details}

Y. Tan, L. Meegahapola \& K. M. Muttaqi , "Suboptimal MPPT control for power management in PV-diesel remote area power supply systems," in Industry Applications Society Annual Meeting, 2014 IEEE, 2014, pp. 1-8. 


\section{Suboptimal MPPT Control for Power Management in PV-Diesel Remote Area Power Supply Systems}

\author{
Yingjie Tan \\ Student Member, IEEE \\ School of Electrical, Computer and \\ Telecommunications Engineering \\ University of Wollongong \\ New South Wales 2500, Australia \\ yt816@uowmail.edu.au
}

\author{
Lasantha Meegahapola \\ Member, IEEE \\ School of Electrical, Computer and \\ Telecommunications Engineering \\ University of Wollongong \\ New South Wales 2500, Australia \\ lasantha@uow.edu.au
}

\author{
Kashem M. Muttaqi \\ Senior Member, IEEE \\ School of Electrical, Computer and \\ Telecommunications Engineering \\ University of Wollongong \\ New South Wales 2500, Australia \\ kashem@uow.edu.au
}

\begin{abstract}
Maximum power point tracking (MPPT) is commonly being used in solar-photovoltaic (PV) power generation systems to maximise solar energy extraction. In this paper it is proposed to operate the solar-PV system at the suboptimal MPPT to manage power balance in a remote area power supply (RAPS) system. This is performed based on three different operating modes: 1) Frequency control mode; 2) Active power control mode; 3) MPPT control mode. The operating modes are decided based on the load level and the operating mode of the diesel generator (i.e. synchronous condenser mode or generator mode). This power management strategy balances the generation and load demand that requires transition between the three operating modes without using the dummy load. The proposed strategy is capable of extending the diesel generator life time and improves the operating efficiency of the diesel generator. Simulation studies are carried out to validate the effectiveness of the suboptimal MPPT control strategy in a PV-Diesel RAPS system, and have shown that the proposed strategy can seamlessly maintain power balance in the RAPS system while maintaining the voltage and frequency within stipulated limits. Substantial cost savings can also be achieved in long run due to the life time extension and efficiency improvement of the diesel generator.
\end{abstract}

Index Terms-Diesel generator, frequency control, maximum power point tracking (MPPT), photovotaic (PV), power management, remote area power supply (RAPS) system, voltage control.

\section{INTRODUCTION}

Remote area power supply (RAPS) systems operate independently from large commercial power systems, and it is an ideal option for electrically "isolated" areas where connection to the utility grid is costly or technically challenging. Diesel has been used as the dominant energy resource in many early RAPS systems [1]. The diesel engine generator (DEG) has the advantage of high reliability, but environmental and economic factors prohibit its continuing expansion. Diesel price is increasing and it puts heavy burden on the electricity consumers. Additionally, greenhouse gas emission and air pollution caused by diesel combustion adversely affect the environment. Another constrain is its poor efficiency under low load condition. Usually, the load in a RAPS system fluctuates frequently, and may result in very low load factor. The DEGs in diesel-only RAPS systems are commonly oversized to meet the peak demand, and operating efficiency can be low during the off-peak period. Therefore, utilisation of renewable energy resources in RAPS systems has gained wide attention.
Solar energy is one of the promising renewable energy resources, and it is gaining popularity among many power utilities around the world. Profiting from its low susceptibility to geographical position, and its ease of installation, solar energy is widely being used in RAPS systems. Moreover, integration of PV arrays reduces the operating cost and greenhouse gas emissions [2]. Maximum power point tracking (MPPT) techniques ensure photovoltaic (PV) generation unit extracting maximum energy from the irradiance on the surface of PV arrays. Variable MPPT techniques have been proposed in the published literature [3, 4], whereas perturbation and observation $(\mathrm{P} \& \mathrm{O})$ method and incremental conductance (IC) method are popular techniques for majority of authors $[5,6]$.

Power management in a RAPS system is more challenging than the utility grid, since there is usually no dominant energy resource in RAPS systems, especially when non-schedulable renewable energy resources are utilised. Both active power and reactive power requirement can be balanced between generation and load demand to achieve frequency and voltage regulation of the RAPS system. Storage system can effectively mitigate the impact of active power fluctuations in a RAPS system. The energy storage component absorbs surplus energy when generation is more than sufficient to supply power to the load, and injects power when energy deficit occurs in the system [7]. Nevertheless, the capital investment for storage system is quite high, and the operation and maintenance $(\mathrm{O} \& \mathrm{M})$ cost also adds to the energy cost. Physical dummy load can be mounted to consume extra energy, preventing the storage system from overcharging [8]; and a dump power control technique was suggested in [9] which alleviates the requirement for a dump load. Reactive power management is vital for voltage regulation in RAPS systems. Synchronous machine (SM) is capable of supplying reactive power through excitation control, and hence the machine can operate as a synchronous condenser to regulate voltage without producing or consuming active power [8]. Electronically interfaced energy resources (e.g. solar-PV, wind generators) can also provide reactive power support [10], however, a large capacitor is required for the inverter.

In [7], authors have proposed to turn off the diesel generator when summation of PV generation and stored energy is adequate to fulfil the load demand, hence the battery energy storage system emulates the grid response while the PV generator operates at the MPPT mode. Therefore, the battery energy storage system is required to supply both active and reactive power for the RAPS system. The PV- 
diesel RAPS system proposed in [11] shares the load demand between the PV generator and the DEG without using an energy storage system. The DEG will supply only a low load demand in comparison to the PV generator in order to maximise the DEG efficiency, however the fuel savings will not be maximised as the DEG supplies power even when the PV generation can fulfil the load demand. Additionally, the maximum power point (MPP) and the operating point for tailored power output are determined using a lookup table which is defined as "quasi seeking" algorithm by [4]. This kind of estimation method depends on the parameters of the PV generator, and the integrity of the empirical data is essential for an accurate estimation.

In this paper, a low cost hybrid RAPS system is built by integrating a PV generator into DEG-dominated RAPS system. Energy storage and dump load are not implemented, and DEG is expected to be operated optimally to maximise the fuel savings. Therefore, a suboptimal MPPT control strategy is proposed for the PV generator to maintain the power balance at the RAPS system. Based on the irradiance level, three operating modes are defined for the PV generator depending on the load level: 1) Frequency control mode; 2) Active power control mode; 3) MPPT control mode. The DEG operating mode (i.e. synchronous condenser mode or generator mode) is determined to coordinate with the PV generator. The RAPS system may transit between different operating modes to match with the variability of the load demand.

The remainder of the paper is organised as follows: Section II presents the system components modelling. Section III discusses the MPPT strategies and the proposed power management strategy. Case studies are presented in Section IV and Section V outlines the concluding remarks.

\section{SYSTEM MODELLING}

The main objective of this study is to integrate PV generator into diesel-dominated RAPS system to maximise fuel savings while excluding the requirement for an energy storage system and a dummy load. The proposed RAPS system is presented in Fig. 1. A two-stage converter converts the DC power generated by the PV array to AC. The boost converter regulates the operating point of the PV array whereas the inverter produces sinusoidal voltages while maintaining the voltage on the DC-link constant. The diesel engine drives the SM through a clutch. When the clutch is engaged, the SM can operate as a generator. Otherwise, the SM operates as a synchronous condenser. The detailed modelling of the PV generator and DEG is discussed in following subsections.

\section{A. PV generator modelling}

Architecture of the proposed PV-diesel RAPS system shown in Fig. 1 consists of PV inverter and boost converter with solar panels, synchronous machine with diesel engine and load. As shown in Fig. 1, the equivalent circuit of a PV module is composed of a current source $I_{s}$, a parallel diode, a parallel resistor $R_{p}$, and a series resistor $R_{s}$. The voltage across the two terminals of the module is $V_{m}$. The mathematical representation of the equivalent circuit has the following form:

$$
I_{m}=I_{s}-\underbrace{I_{r}\left[\exp \left(\frac{q\left(V_{m}+I_{m} R_{s}\right)}{\eta k T}\right)-1\right]}_{I_{d}}-\underbrace{\frac{V_{m}+I_{m} R_{s}}{R_{p}}}_{I p}
$$

where $I_{m}$ is the module output current and $I_{s}$ is the photocurrent which is proportional to the solar irradiance. The $I_{p}$ is the current through the parallel resistance and $I_{d}$ through the diode. $I_{r}$ is the diode reverse saturation current, $q$ is the electrical charge $\left(1.6 \times 10^{-19} \mathrm{C}\right), \eta$ is the $\mathrm{p}-\mathrm{n}$ junction quality factor, $k$ is the Boltzmann constant $\left(1.38 \times 10^{-23} \mathrm{~J} / \mathrm{K}\right)$, and $T$ is the ambient temperature (in Kelvins).

To obtain the required power output, a multitude of PV modules are connected in series and in parallel to form PV arrays. The terminal voltage of the PV arrays symbolised as $V$ in Fig. 1. The electrical parameters of the PV module used in this paper under standard test conditions (STC) are listed in the Appendix. The nonlinear current-voltage relationship of the PV module, which is known as the $I-V$ photovoltaic characteristics, is presented by the dashed curves in Fig. 2. Hence, the relationship between power output and terminal voltage, which is defined as PV power characteristic, can also be determined and shown as solid curves in Fig. 2. It can be seen from the power characteristic curve that the MPP marked with red circle, presents for each solar irradiation level. The MPP can be tracked with a MPPT strategy to maximise the solar energy extraction.

Voltage oriented vector control [10] is a common method to control the interface inverter of the PV generator. If the direct-quadrant $(d-q)$ reference frame rotates synchronously with $\mathrm{d}$-axis aligned with grid voltage, then the active power and reactive power supplied by the inverter can be controlled by the d-axis component and q-axis component of the current respectively, which is given by:



Fig. 1. Architecture of the PV-diesel RAPS system. 


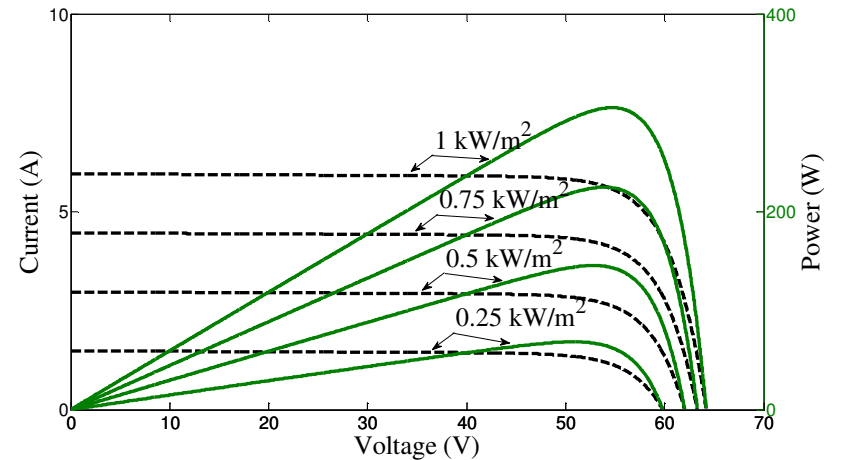

Fig. $2 \mathrm{I}$ - $\mathrm{V}$ characteristic and power characteristic of a PV module.

$$
\begin{aligned}
& P_{P V}=\frac{3}{2} v_{p d} i_{p d} \\
& Q_{P V}=-\frac{3}{2} v_{p d} i_{p q}
\end{aligned}
$$

where $P_{P V}$ and $Q_{P V}$ are the active and reactive power respectively, $i_{p d}$ and $i_{p q}$ are d-axis and q-axis component of the current, and $v_{p d}$ is the d-axis component of voltage at the point where PV generator connects to the grid. The voltage equations in the $\mathrm{d}-\mathrm{q}$ reference frame take the form:

$$
\begin{aligned}
& v_{d}=L_{f} \frac{d i_{p d}}{d t}-L_{f} \omega_{0} i_{p q}+R_{f} i_{p d}+v_{p d} \\
& v_{q}=L_{f} \frac{d i_{p q}}{d t}-L_{f} \omega_{0} i_{p d}+R_{f} i_{p q}+v_{p q}
\end{aligned}
$$

where $v_{d}$ and $v_{\mathrm{q}}$ are the $\mathrm{d}$-axis and q-axis component of the inverter output voltage respectively, $R_{f}$ and $L_{f}$ are the interfacing filter resistance and inductance respectively, $\omega_{0}$ is the synchronous frequency, and $v_{p q}$ is the q-axis component of the PV generator terminal voltage. With d-axis of the d-q reference frame aligns with the grid voltage, $v_{p q}$ normally equals to zero. When $R_{f}$ is small compared with $L_{f}$, the $R_{f}$ term can be neglected.

In this study, DEG supplies the entire reactive power required in the RAPS system as PV generator produces no reactive power. Hence, the q-axis current reference $i_{q r}$ is set to zero. In this regard the reference of the d-axis current component $i_{d r}$ is generated from the DC-link voltage regulator. A proportional-integral (PI) controller is used to regulate the inverter input $\mathrm{DC}$ voltage $V_{D C}$ to the reference value $V_{D C r}$ and generate the d-axis current reference. Therefore, the controller for the inverter can be described using the block diagram in Fig. 3 and main parameters of the inverter are listed in Appendix.

\section{B. Diesel engine generator modelling}

The diesel engine consumes fuel and produces mechanical torque based on the governor response. The basic block diagram shown in Fig. 4 models the controller with a secondorder transfer function, and the fuel injection actuator with a third-order transfer function. A time delay $T_{D}$ is added into the model to represent the time delay between the fuel injection and mechanical torque developed at the shaft of the diesel engine [12]. As claimed in [13], the engine speed in per unit is approximated by:

$$
\omega=\frac{1}{2 H_{d}} \int\left(T_{d}-T_{c}\right) d t
$$

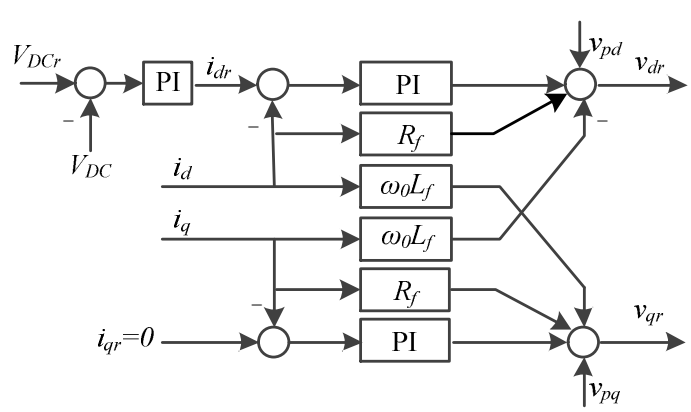

Fig. 3 Block diagram of the PV inverter controller.

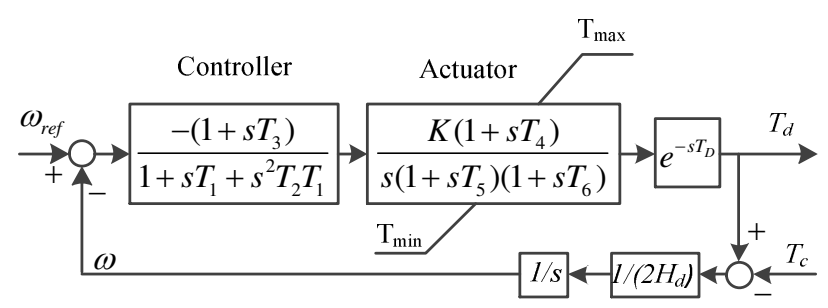

Fig. 4 Diesel engine and governor block diagram.

where $H_{d}$ is the diesel engine inertia constant, $T_{d}$ is the engine mechanical torque, and $T_{c}$ is the transmitted torque from engine to $\mathrm{SM}$ which is given by:

$$
T_{c}= \begin{cases}0, & \text { Clutch disengaged } \\ \frac{H_{s} T_{d}+H_{d} T_{s}}{H_{s}+H_{d}}, & \text { Clutch engaged }\end{cases}
$$

where $H_{s}$ and $T_{s}$ are the inertia constant and electrical torque of the SM respectively.

The exciter of the SM given in [14] is used for this study. The main parameters of the diesel engine generator are given in the Appendix.

\section{POWER MANAGEMENT STRATEGY}

Both the DEG and the PV generator are capable of managing active and reactive power as described in Section II. DEG regulates the active and reactive power through diesel engine governor and SM exciter respectively, whereas $\mathrm{d}$-axis and q-axis components of inverter current control the active power and reactive power from the PV generator respectively. This section presents the traditional power management strategy for the PV generator, and the proposed power management strategy for the PV-Diesel RAPS system.

\section{A. MPPT strategy for Solar-PV}

In grid-connected PV generation systems, the MPPT is a common approach to determine the optimal operating point to maximise the solar energy extraction. The PV generation system operates as a current source while extracting maximum energy from the solar irradiance. If required, the PV generator can provide voltage support for the grid by supplying or absorbing reactive power. The perturbation and observation $(\mathrm{P} \& \mathrm{O})$ method, and incremental conductance (IC) method are two commonly used MPPT strategies for solar-PV systems. The $\mathrm{P} \& \mathrm{O}$ method is implemented by imposing periodic positive or negative perturbations for the terminal voltage of the PV array. If the varying direction (increase or decrease) of the PV output power is the same 
with the varying direction of the terminal voltage, then the same voltage perturbation is applied to the next step. Otherwise, a voltage perturbation of opposite polarity with the present step perturbation is imposed in the next step. The $\mathrm{P} \& \mathrm{O}$ has the advantage of ease of implementation whereas sudden irradiance variation may confuse the controller and oscillations around the MPP are inevitable [15]. The IC algorithm is claimed to be able to overcome the drawbacks of $\mathrm{P} \& \mathrm{O}$ [15]. IC is based on the fact that the derivative of the power with respect to the voltage at MPP is zero. Hence, the following equation is derived.

$$
\frac{d I}{d V}+\frac{I}{V}=0
$$

By adding a simple PI controller, the IC method performance can be improved with less oscillation in steady-state and improve the tracking performance [3].

\section{B. Proposed Suboptimal MPPT strategy}

In a PV-diesel RAPS system without energy storage, if the typical MPPT strategy is implemented, dummy load should be used to consume the surplus energy when the generation is greater than load demand. In addition, DEG may operate at a very light loading level when the PV generator is operating at the MPP, which deteriorates the DEG life time and operating efficiency. Therefore, it is beneficial for the PV generator to tailor its power output deliberately in some situations, i.e. operating at suboptimal power point. In this way, dummy load can be eliminated whereas low loading limit can also be guaranteed for the DEG. Consequently, DEG life time can be prolonged and operating efficiency can be improved. In this paper, IC MPPT algorithm is used to detect the MPP at a particular irradiation level and stores the maximum power value $P_{M P P}$. Based on the comparison between the maximum power and load demand $P_{\text {load }}$, a proper operating mode for the PV generator can be chosen from the three possible operating modes:

1) If the maximum power is larger than load demand, the PV generator operates in frequency control mode and shifts to a suboptimal operating point to match with the load.

$$
P_{M P P}>P_{\text {load }}
$$

2) If the maximum power is less than the load by more than the designed minimum loading level, the PV generator runs in the MPPT mode.

$$
P_{M P P}<P_{\text {load }}-P_{\text {min }}
$$

3) If the load drops in the range between the previous two cases, power control mode is applied to the PV generator and results in a suboptimal operating point.

$$
P_{\text {load }}-P_{\text {min }}<P_{M P P}<P_{\text {load }}
$$

The decision making process is illustrated in Fig. 5.

\section{Power management in PV-diesel system}

Both the PV generator and the diesel generator are capable of providing voltage support to the RAPS system. However, by demanding reactive power from the PV generator, the PV interfacing inverter requires additional MVA capacity. Contrarily, SM absorbs or injects reactive power through excitation control. Therefore, the DEG has been assigned for reactive power management.
As far as active power is concerned, the RAPS system may operate in following three different modes depending on the operating mode of the PV generator.

Mode I: If the PV generator operates in frequency control mode, no active power is demanded from the DEG. However, SM should operate in synchronous condenser mode to regulate voltage in the RAPS system though excitation control. The clutch mounted on the diesel engine shaft and the SM shaft is disengaged to separate the SM from the diesel engine, and the diesel engine is shutdown. The PV generator establishes the RAPS system frequency and supplies active power to match with load. As shown in Fig. 6, by shifting the PV array terminal voltage on the power characteristic curve, the power output can be adjusted to a suboptimal point to match with the load. The left side of the MPP is chosen for power regulation.

Mode II: In this mode as indicated by the diagonal-line shaded region of Fig. 6, the load satisfies (9). In order to reduce the operation and maintenance (O\&M) cost, the loading level of the diesel engine generator is expected to be above a predesigned value. Hence, power control mode forces PV generator to compromise the MPPT strategy and adjusts its operating point to ensure minimum loading for the DEG. The active power setting for the PV generator is defined by:

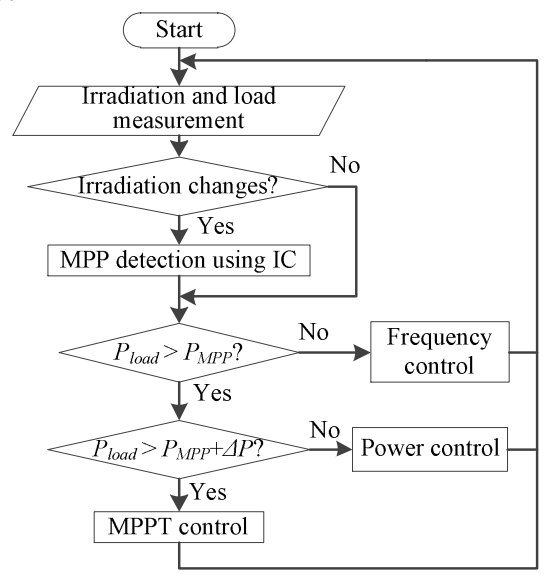

Fig. 5 Suboptimal MPPT control strategy.



Fig. 6 PV-Diesel RAPS system operating modes.

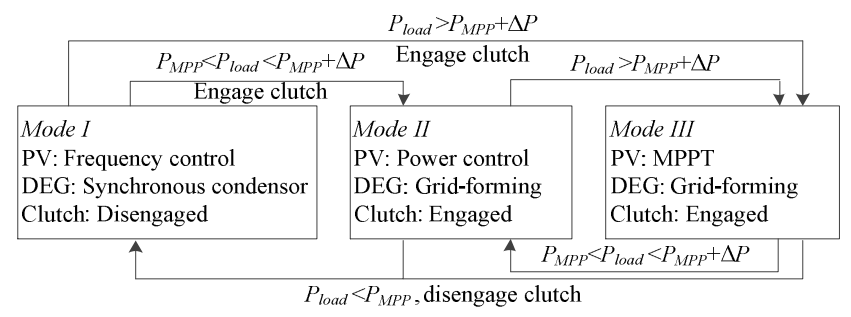

Fig. 7 RAPS system operating mode transition. 


$$
P_{P V}=P_{\text {load }}-P_{\min } .
$$

The DEG operates in grid-forming mode and regulates both the frequency and voltage in the system. The clutch connecting engine shaft and machine shaft should be engaged to transfer mechanical torque from the engine to the machine.

Mode III: When load demand exceeds $\left(P_{M P P}+P_{\text {min }}\right)$ as shown in the diamond shaded region of Fig. 6, PV generator can operate at the MPP, whereas DEG is loaded above its lower loading limit. Like Mode II, DEG establishes the RAPS system and manipulates system frequency and voltage by diesel engine governor and SM excitation control. PV generator is controlled under MPPT strategy. Clutch needs to be engaged in this mode as with Mode II. The active power produced by diesel generator can be determined using:

$$
P_{d}=P_{\text {load }}-P_{M P P}
$$

The details of the transition logic between the system operating modes mentioned above are illustrated in Fig. 7.

\section{Clutch control}

Clutch transforms RAPS system operation mode from Mode I to other two modes or from other two modes to Mode $I$. When the clutch is engaged, the SM rotates at the same speed as the diesel engine, and the engine drives the machine to operate in generator mode. When the clutch is disengaged, the two shafts rotate at their own speeds, and the machine operates at the synchronous condenser mode without generating any active power. The PV maximum power is compared with the load, if the load is less than the maximum power, then the clutch disengages. Otherwise, clutch should be engaged. To engage the clutch, the following two requirements should be satisfied.

1) Load demand is greater than the maximum available PV power.

$$
P_{\text {load }}>P_{M P P}
$$

2) The speed difference of the diesel engine shaft and SM shaft should be less than $\varepsilon$, i.e.

$$
\left|\omega_{d}-\omega_{s}\right|<\varepsilon
$$

where $\varepsilon$ is taken as $10^{-5}$ [13] in this paper. The clutch controller is presented in Fig. 8.

\section{CASE STUDIES}

A RAPS system with PV generator and diesel engine generator is built in MATLAB/Simulink using the SimPowerSystems toolbox. The diesel generator has a capacity of $275 \mathrm{kVA}$ and PV generator is rated at $100 \mathrm{~kW}$ under STC. The size of the system components can be determined using the approach used in [16]. The component sizing is processed in an iterative manner until the system reliability denoted by loss of load expectation (LOLE) meets designated level.

The lower loading limit of the DEG is set to be $30 \mathrm{~kW}$ ( $10 \%$ of the capacity of diesel generator). Since the purpose of this study is to evaluate the power management performance of the RAPS system, the impact of temperature on PV system is not considered and the temperature of the PV cells is considered to be $25{ }^{\circ} \mathrm{C}$. Case studies are

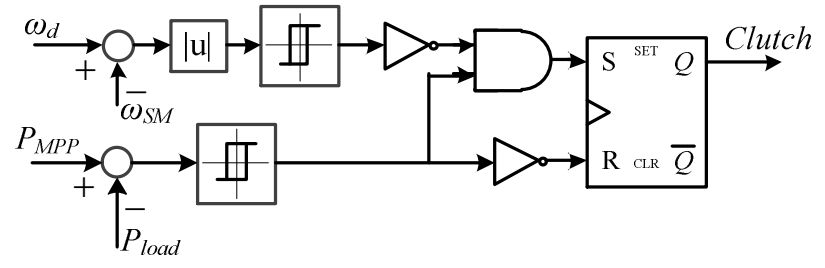

Fig. 8 Clutch controller.

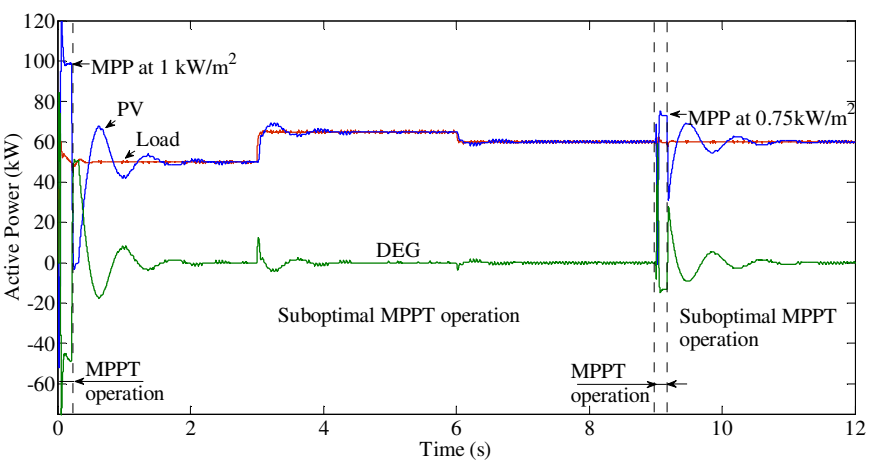

(a)

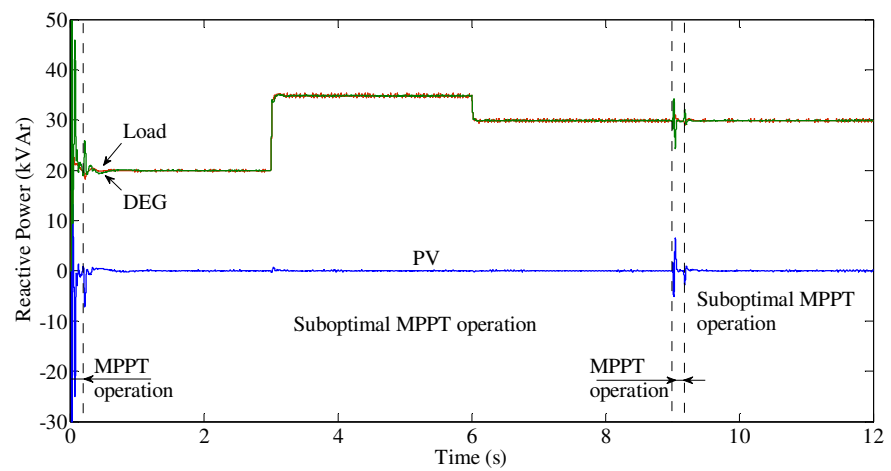

(b)

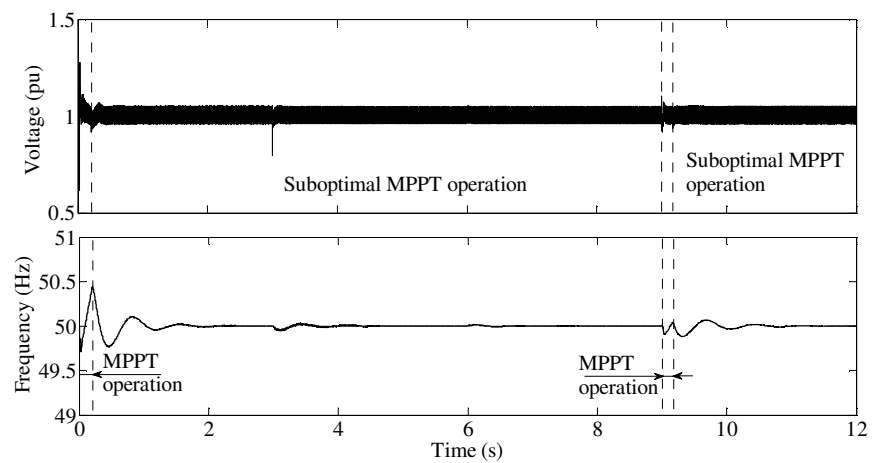

(c)

Fig. 9 Mode I operation with variable irradiance. (a) Active power management; (b) Reactive power management; (c) Voltage and frequency regulation.

conducted to evaluate the transition process among the three operating modes with the proposed suboptimal MPPT control approach in the PV-diesel RAPS system.

\section{A. Case A: RAPS System Mode I operation with variable} solar irradiance

This case study demonstrates the PV-system's capability to track maximum power from the solar as well as to adjust its power output to match with load. Generally, when solar irradiance change is detected by the PV system, the PV system transits to MPPT control mode and the maximum 
available power can be determined. If the maximum power is higher than the load, then the PV system lowers its power output accordingly. The simulation starts with a solar irradiance of $1 \mathrm{~kW} / \mathrm{m}^{2}$ and the total load of $50 \mathrm{~kW}+\mathrm{j} 20$ $\mathrm{kVAr}$. The MPP is detected as $100 \mathrm{~kW}$ which is above the load active power. Hence, the RAPS system transits to operate in suboptimal MPPT mode at around $t=0.2 \mathrm{~s}$. The PV supplies all the active power demand of the load while maintaining system frequency, hence the active power output of the DEG is zero as shown in Fig. 9-(a). The load changes to $65 \mathrm{~kW}+\mathrm{j} 35 \mathrm{kVAr}$ at $\mathrm{t}=3 \mathrm{~s}$ and is lowered by $5 \mathrm{~kW}+\mathrm{j} 5$ $\mathrm{kVAr}$ at $\mathrm{t}=6 \mathrm{~s}$. The load is accurately tracked by the generation in the process until solar irradiance lowers to 0.75 $\mathrm{kW} / \mathrm{m}^{2}$ at $\mathrm{t}=9 \mathrm{~s}$. The PV senses the MPP again and returns to suboptimal MPPT operation mode as the available maximum solar power is around $75 \mathrm{~kW}$, which is still larger than active power demand of the load. As it can be seen in Fig. 9-(b), the DEG supplied all the reactive power demand in the RASPS system by running at the SC mode during the $12 \mathrm{~s}$ time period. Fig. 9-(c) shows that the voltage is regulated in the range of $(1 \pm 0.05) \mathrm{pu}$ and frequency is within $(50 \pm 1.0) \mathrm{Hz}$.

\section{B. Case B: RAPS System operating mode transition between Mode I and Mode II}

In this case study, the RAPS system operates originally in Mode $I$ with a load of $85 \mathrm{~kW}+\mathrm{j} 35 \mathrm{kVAr}$ and solar irradiance is $1 \mathrm{~kW} / \mathrm{m}^{2}$. At $\mathrm{t}=6 \mathrm{~s}$, the load increases by $20 \mathrm{~kW}$. Since the load active power exceeds the maximum power from the PV system while the power gap between the load and the PV generation is lower than the designated minimum loading level of the DEG, the RAPS system should operate in Mode II to improve DEG efficiency and the life time. That is, the PV system is deliberately manipulated to operate at a suboptimal MPP to ensure minimum loading level is assigned to the DEG. As shown in Fig. 10-(a), the PV generator supplies $75 \mathrm{~kW}$ while the DEG is loaded at 30 $\mathrm{kW}$ after the transit period. Another load of $5 \mathrm{~kW}+\mathrm{j} 5 \mathrm{kVAr}$ is added into the system at $\mathrm{t}=13 \mathrm{~s}$. The PV system increases the power output to meet the extra load and the DEG maintains its power output at $30 \mathrm{~kW}$. At $\mathrm{t}=16 \mathrm{~s}$, load returns to the original level $(85 \mathrm{~kW}+\mathrm{j} 35 \mathrm{kVAr})$ and the RAPS system transits back to Mode I. Similar to Mode I, reactive power of the system is totally supplied by the DEG as illustrated in Fig. 10-(b).

Fig. 10-(c) presents the system voltage and frequency. The transition has an insignificant impact on the voltage, but frequency during the transition from Mode I to Mode II goes through a transient process. The frequency decreases when load becomes higher than generation until the DEG is started to eliminate the power gap. The detailed SM and DEG operation during the transition process is illustrated in Fig. 10-(d). At $t=6 \mathrm{~s}$, the clutch engaging condition (12) is fulfilled. At this stage, the cranking system is usually switched on to raise the engine speed to firing speed. Firing speed is taken to be 0.3 pu in this study. In order to simplify the simulation of cranking process, the diesel engine is running at firing speed rather than being shut down when it is not driving the SM, and a time delay of $0.5 \mathrm{~s}$ is added to represent the cranking time period [13]. Hence, the diesel engine is fired at $\mathrm{t}=6.5 \mathrm{~s}$ and the speed increases under the control of diesel governor. Meanwhile, since the PV generation is not enough to power load, the inertial energy stored in the SM's rotating mass releases, and SM speed deceases. At $t=7.8 \mathrm{~s}$, the clutch engaging requirement (13) is also satisfied and the clutch engages. Afterwards, the diesel engine and the SM operate at the same speed and recover the rotational speed to nominal value. During the transition period, in order to minimise the frequency excursion, $\mathrm{PV}$ is controlled to operate at the MPPT mode to eject as much energy as possible, which can be seen from Fig. 10-(a).

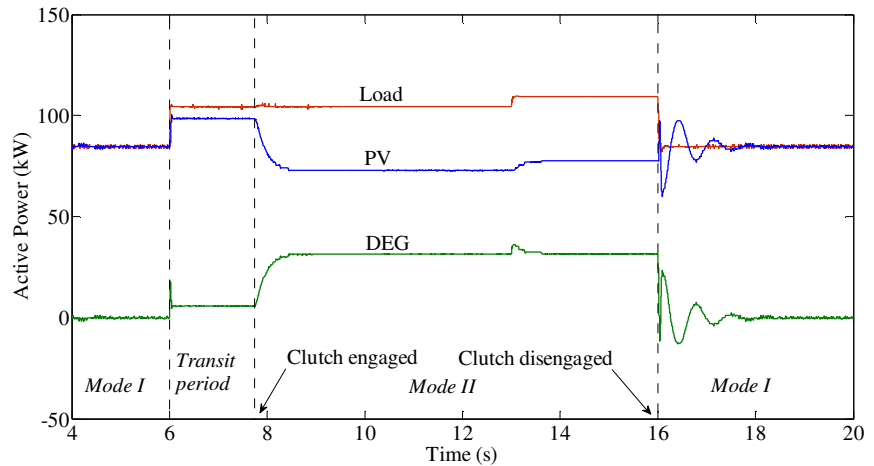

(a)

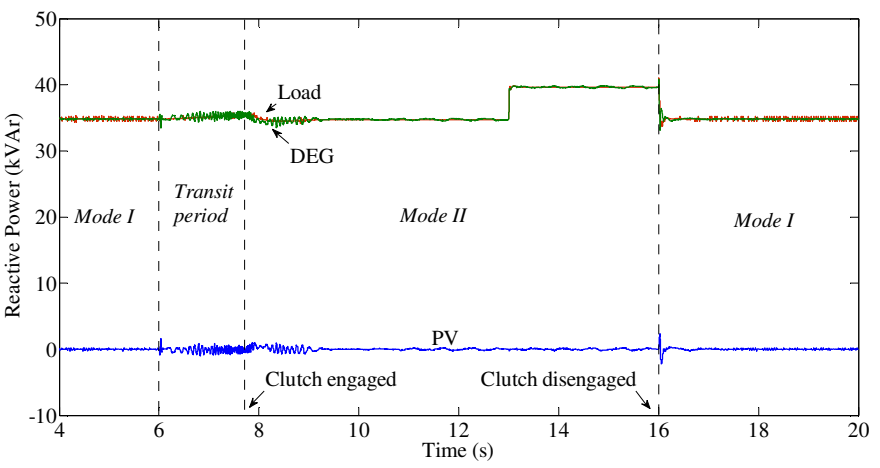

(b)
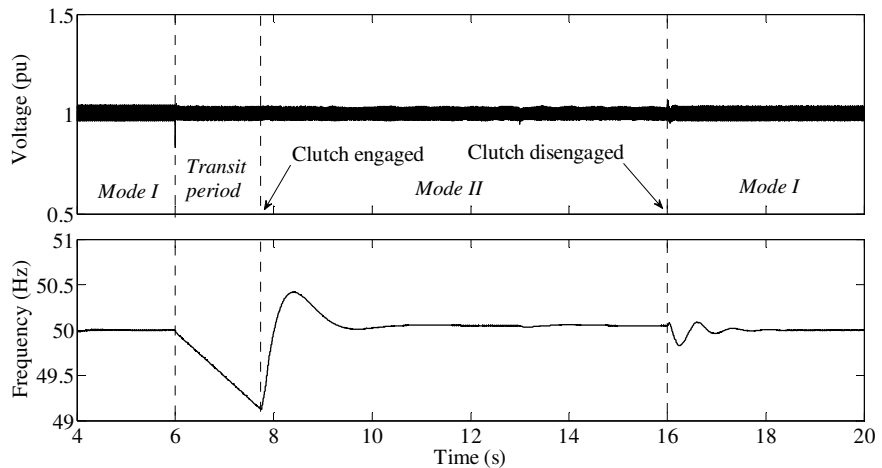

(c)



(d)

Fig. 10 Operation mode transition between Mode I and Mode II. (a) Active power management; (b) Reactive power management; (c) Voltage and frequency regulation; (d) Transition period. 


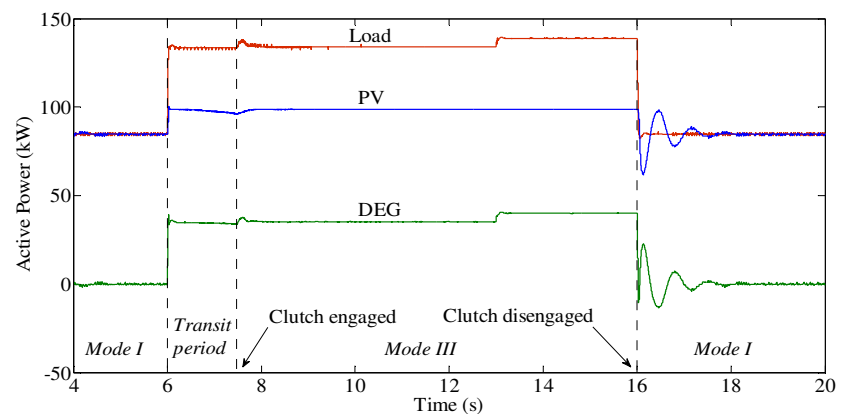

(a)



(b)

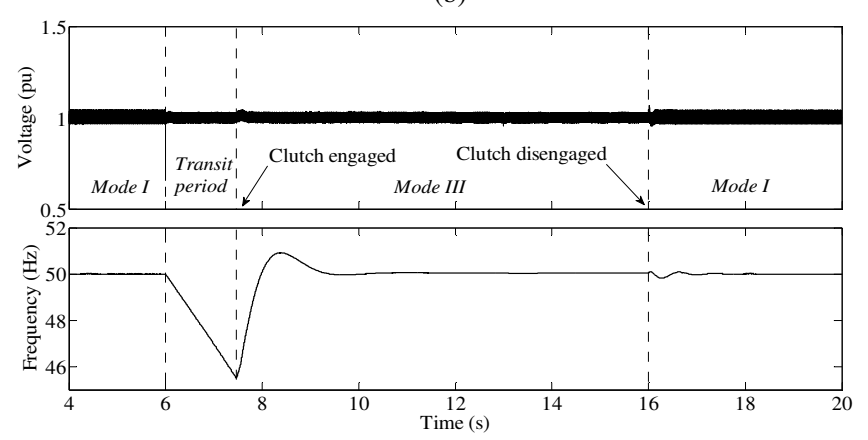

(c)

Fig. 11 Operating mode transition between Mode I and Mode III. (a) Active power management; (b) Reactive power management; (c) Voltage and frequency regulation.

\section{Case C: RAPS System operating mode transition between Mode I and Mode III}

Similar to the transition between Mode I and Mode II, SM transits between synchronous condenser mode and generator mode when the system transits between Mode I and Mode III. The only difference is that MPPT strategy is applied only during the transit period from Mode I to Mode II, and suboptimal MPPT approach is used when the clutch is engaged. However, the MPPT control strategy is applied during transit period from Mode I to Mode III as well as under Mode III operation.

As it can be seen from Fig. 11-(a), the simulation is also started with the load $85 \mathrm{~kW}+\mathrm{j} 35 \mathrm{kVAr}$. Hence, the system operates in Mode $I$ at the beginning as similar to Case B. At $\mathrm{t}$ $=6 \mathrm{~s}$, the load demand increases to $135 \mathrm{~kW}+\mathrm{j} 35 \mathrm{kVAr}$. The active power demand is more than the addition of the maximum PV generation, and designated value of the minimum loading level for the DEG. The system goes through the transition process and then operates in Mode III. The PV generates maximum power (i.e. $100 \mathrm{~kW}$ ) through the MPPT control and maintains the power output even when a load of $5 \mathrm{~kW}+\mathrm{j} 5 \mathrm{kVAr}$ is added to the system at $\mathrm{t}=13 \mathrm{~s}$.
With frequency control, the DEG shifts its power output to fulfil the power gap between the load demand and the PV generation. After $\mathrm{t}=16 \mathrm{~s}$, the PV system is controlled to operate in Mode $I$ when the load is reduced to $85 \mathrm{~kW}+\mathrm{j} 35$ kVAr. Fig. 11-(b) indicates that the reactive power is managed as expected, i.e. PV generator injects no reactive power and the DEG produces the entire reactive power requirement for the RAPS system. Similar to Case $B$, frequency deviation occurs during the transition period from Mode I to Mode III due to the lack of energy resources as presented in Fig. 11-(c).

\section{Case D: RAPS System operating mode transition between Mode II and Mode III}

The RAPS system transits from Mode II to Mode III if condition (10) is met. Under these two operation modes, DEG plays grid-forming role and no change is required for the DEG control. With regard to the PV, it operates under suboptimal MPPT condition in Mode II. The MPPT control can be implemented in Mode III to extract maximum power from the solar-PV while the minimum loading level can be guaranteed for the DEG. As shown in Fig. 12-(a), the system is originally loaded at $120 \mathrm{~kW}+\mathrm{j} 40 \mathrm{kVAr}$. When the load increases by $20 \mathrm{~kW}+\mathrm{j} 5 \mathrm{kVAr}$, the PV transits to operate in MPPT strategy and export $100 \mathrm{~kW}$ power under the irradiance of $1 \mathrm{~kW} / \mathrm{m}^{2}$ and maintains the maximum power output until the system transits back to Mode $I I$ at $\mathrm{t}=22 \mathrm{~s}$, when load changes to the original level. The DEG supplies power to fulfil the power gap between load and PV generation. The active power output of the DEG is $40 \mathrm{~kW}$ during $16 \mathrm{~s}$ to $19 \mathrm{~s}$, and increases to $45 \mathrm{~kW}$ during $19 \mathrm{~s}$ to $22 \mathrm{~s}$ when a load of $5 \mathrm{~kW}+\mathrm{j} 0 \mathrm{kVAr}$ is added to the system. After transiting back to Mode II, the DEG provides designated minimum active power $(30 \mathrm{~kW})$. As with other cases, it can be concluded from Fig. 12-(b) that the DEG supplies reactive power for the whole system. Under the regulation of the DEG, frequency and voltage fluctuations are manipulated in a narrow range as indicated by Fig 12-(c).

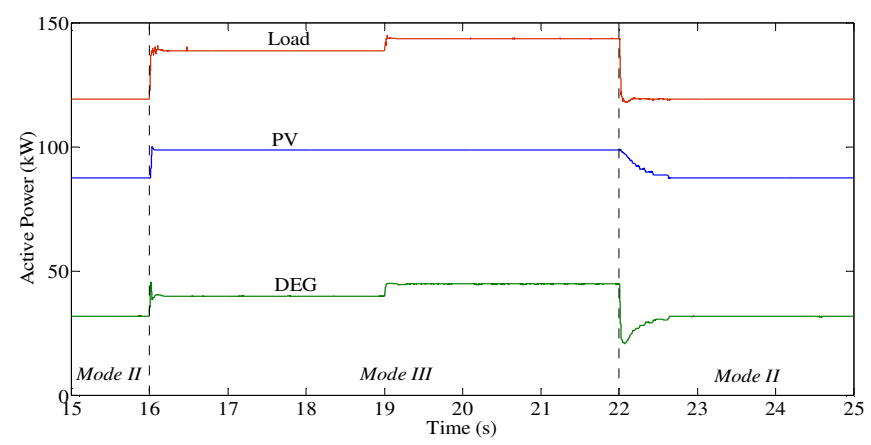

(a)



(b) 


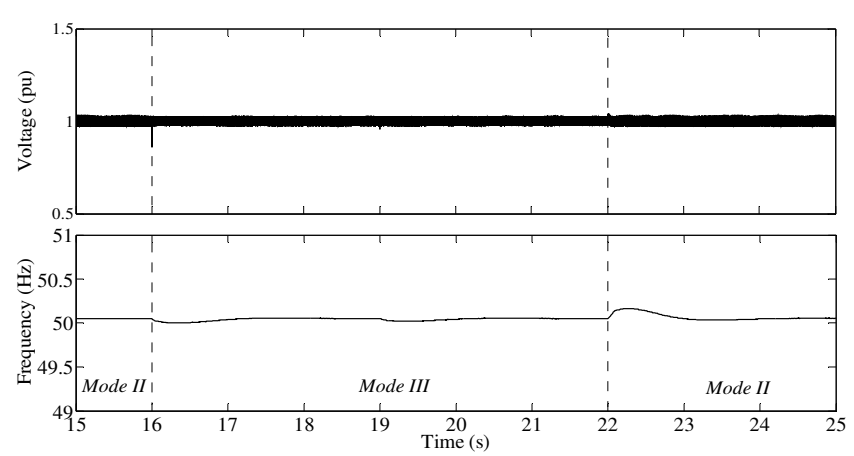

(c)

Fig. 12 Operating mode transition between Mode II and Mode III. (a) Active power management; (b) Reactive power management; (c) Voltage and frequency regulation.

\section{CONCLUSION}

This paper proposed a suboptimal MPPT control strategy for a solar-PV generator to maintain power balance in a PVdiesel RAPS system. The proposed control strategy determines the PV generator operating mode and thus the operating mode of the diesel generator. Three combinations of the PV generator and diesel generator modes constitute three power management modes. The optimal coordination between PV generator and diesel generator balances both active and reactive power in the RAPS system by transiting among the three power management modes in accordance with the load change. Voltage is well regulated through synchronous machine excitation control. Frequency excursion is maintained around nominal value except during diesel generator starting period when sudden large power deficiency occurs in the system. The frequency excursion depends on the power deficiency value and the response speed of the diesel generator. The effectiveness of the proposed power management strategy haves been investigated through simulation studies. The simulation results indicated that accurate active power and reactive power management can be achieved with the proposed suboptimal control strategy.

\section{APPENDIX}

\section{TABLE I}

ELECTRICAL PARAMETERS OF THE PV MODULE

\begin{tabular}{lc}
\hline \hline Parameter & Value \\
Open Circuit Voltage (V) & 64.2 \\
Short Circuit Current (A) & 5.96 \\
Voltage at MPP (V) & 54.7 \\
Current at MPP (A) & 5.58 \\
\hline \hline
\end{tabular}

TABLE II

DIESEL ENGINE GENERATORPARAMETERS

\begin{tabular}{lccc}
\hline \hline Parameter & Value & Parameter & Value \\
Rated Power (KVA) & 275 & T1 & 0.01 \\
Rated Speed (rpm) & 1500 & T2 & 0.02 \\
Rated Voltage (V) & 400 & T3 & 0.2 \\
\hline \hline
\end{tabular}

\begin{tabular}{llll}
\hline \hline Pole Pairs & 2 & $\mathbf{T 4}$ & 0.25 \\
$\mathbf{H}_{\mathbf{d}}(\mathbf{s})$ & 0.75 & $\mathbf{T 5}$ & 0.009 \\
$\mathbf{T}_{\mathbf{D}}(\mathbf{s})$ & 0.024 & $\mathbf{T 6}$ & 0.0384 \\
$\mathbf{H}_{\mathbf{s}}(\mathbf{s})$ & 1 & $\mathbf{K}$ & 40 \\
\hline \hline
\end{tabular}

TABLE III

ELECTRICAL PARAMETERS OF THE INVERTER

\begin{tabular}{llll}
\hline \hline \multicolumn{1}{c}{ Parameter } & Value & \multicolumn{1}{c}{ Parameter } & Value \\
Rated Voltage $(\mathbf{V})$ & 400 & $\mathbf{R}_{\mathbf{f}}(\mathbf{O h m s})$ & 0.0067 \\
Rated DC Voltage $(\mathbf{V})$ & 700 & $\mathbf{L}_{\mathbf{f}}(\mathbf{m H})$ & 0.71 \\
Switching Frequency $(\mathbf{H z})$ & 1650 & $\mathbf{C}_{\mathbf{f}}(\mathbf{u F})$ & 200 \\
\hline \hline
\end{tabular}

\section{REFERENCES}

[1] M. Arriaga, C. A. Canizares, and M. Kazerani, "Renewable energy alternatives for remote communities in northern ontario, canada," IEEE Trans. Sustain. Energy, vol. 4, no. 3, pp. 661-670, 2013.

[2] R. W. Wies, R. A. Johnson, A. N. Agrawal, and T. J. Chubb, "Simulink model for economic analysis and environmental impacts of a pv with diesel-battery system for remote villages," IEEE Trans. Power Syst., vol. 20, no. 2, pp. 692-700, 2005.

[3] M. A. G. de Brito, L. Galotto, L. P. Sampaio, G. de Azevedo e Melo, and C. A. Canesin, "Evaluation of the main mppt techniques for photovoltaic applications," IEEE Trans. Ind. Electron., vol. 60, no. 3, pp. 1156-1167, 2013.

[4] V. Salas, E. Olías, A. Barrado, and A. Lázaro, "Review of the maximum power point tracking algorithms for stand-alone photovoltaic systems," Solar Energy Materials and Solar Cells, vol. 90, no. 11, pp. 1555-1578, 2006.

[5] M. A. Elgendy, B. Zahawi, and D. J. Atkinson, "Assessment of perturb and observe mppt algorithm implementation techniques for pv pumping applications," IEEE Trans. Sustain. Energy, vol. 3, no. 1, pp. 21-33, 2012.

[6] M. Qiang, S. Mingwei, L. Liying, and J. M. Guerrero, "A novel improved variable step-size incremental-resistance mppt method for $\mathrm{pv}$ systems," IEEE Trans. Ind. Electron., vol. 58, no. 6, pp. 2427-2434, 2011.

[7] A. Urtasun, P. Sanchis, D. Barricarte, and L. Marroyo, "Energy management strategy for a battery-diesel stand-alone system with distributed pv generation based on grid frequency modulation," Renew. Energy, vol. 66, no. 0, pp. 325-336, 2014.

[8] N. Mendis, K. M. Muttaqi, S. Perera, and M. N. Uddin, "A novel control strategy for stand-alone operation of a wind dominated raps system," in Proc. Industry Applications Society Annual Meeting (IAS), 2011 IEEE, 2011, pp. 1-8.

[9] T. Hirose and H. Matsuo, "Standalone hybrid wind-solar power generation system applying dump power control without dump load," IEEE Trans. Ind. Electron., vol. 59, no. 2, pp. 988-997, 2012.

[10] R. Iravani and A. Yazdani, Voltage-sourced converters in power systems. Hoboken, NJ, USA: Wiley, 2010.

[11] A. Elmitwally and M. Rashed, "Flexible operation strategy for an isolated pv-diesel microgrid without energy storage," IEEE Trans. Energy Convers., vol. 26, no. 1, pp. 235-244, 2011.

[12] K. E. Yeager and J. R. Willis, "Modeling of emergency diesel generators in an 800 megawatt nuclear power plant," IEEE Trans. Energy Convers., vol. 8, no. 3, pp. 433-441, 1993.

[13] R. Sebastián, "Smooth transition from wind only to wind diesel mode in an autonomous wind diesel system with a battery-based energy storage system," Renew. Energy, vol. 33, no. 3, pp. 454-466, 2008.

[14] Y. Tan, K. Muttaqi, and L. Meegahapola, "A droop control based load sharing approach for management of renewable and non-renewable energy resources in a remote power system," in Proc. Australasian Universities Power Engineering Conference(AUPEC), Hobart, 2013.

[15] A. Yazdani, A. R. Di Fazio, H. Ghoddami, M. Russo, M. Kazerani, J. Jatskevich, K. Strunz, S. Leva, and J. A. Martinez, "Modeling guidelines and a benchmark for power system simulation studies of three-phase single-stage photovoltaic systems," IEEE Trans. Power Del., vol. 26, no. 2, pp. 1247-1264, 2011.

[16] Y. Tan, K. Muttaqi, and L. Meegahapola, "Impact of capacity value of renewable energy resources on raps system energy management," in Proc. IET Renewable Power Generation Conference(RPG), Beijing, 2013. 